\title{
Suppression of neuroinflammation by an allosteric agonist and positive allosteric modulator of the $\alpha 7$ nicotinic acetylcholine receptor GAT107
}

Tehila Mizrachi', Oshrit Marsha', Karen Brusin, Yael Ben-David², Ganesh A. Thakur ${ }^{3}$, Adi Vaknin-Dembinsky', Millet Treinin ${ }^{2}$ and Talma Brenner ${ }^{1^{*}}$

\begin{abstract}
Background: The a7 nicotinic acetylcholine receptor ( $a 7$ nAChR) negatively regulates the synthesis and release of pro-inflammatory cytokines by immune cells. Our previous studies showed that in encephalitogenic $T$ cells, a7 nAChR expression is upregulated and that activation of the cholinergic system can attenuate experimental autoimmune encephalomyelitis (EAE). GAT107 is an allosteric agonist and positive allosteric modulator (ago-PAM) of a7 nAChR that can produce persistent activation of this receptor. Therefore, in the present study, we investigated the effect of GAT107 on neuroinflammation in EAE, the animal model used for the study of multiple sclerosis (MS) via a7 nAChR, and the inflammatory pathways involved.
\end{abstract}

Methods: EAE was induced by administration of myelin oligodendrocyte glycoprotein ( $\mathrm{MOG}_{35-55}$ ) in C57BL/6 mice. EAE mice were treated with the ago-PAM GAT107 or a placebo for 9 days, starting from the day of EAE induction. Clinical assessment and immunological evaluation of immune cells and cytokine production was performed.

Results: Following activation of the a7 nAChR by GAT107 during EAE, disease severity was significantly reduced by $70 \%$ and was correlated with a reduction in the extent of neuroinflammation in the CNS. The treatment reduced encephalitogenic T cell proliferation and the production of pro-inflammatory cytokines, as well as increased the production of the anti-inflammatory cytokine IL-10. Furthermore, the expression of immune cell markers was altered by GAT107 treatment, which induced a significant reduction in macrophages, dendritic cells, and B cells, as well as a reduction in anti-MOG ${ }_{35-55}$ antibodies. Additionally, GAT107 was found to directly activate a7 nAChR in murine macrophage RAW264.7 cells and in human PBMCs derived from MS patients and healthy donors.

Conclusions: Our results show that GAT107 can be a useful molecule for harnessing the cholinergic antiinflammatory pathway for long-lasting and wide-ranging modulation and downregulation of neuroinflammation in EAE.

Keywords: a7 Nicotinic acetylcholine receptor, Selective allosteric agonist for a7 nAChR, Multiple sclerosis, B cells, Central nervous system inflammation, Immune cholinergic system

\footnotetext{
* Correspondence: brenner@mail.huji.ac.il

'Department of Neurology, The Agnes Ginges Center for Human

Neurogenetics, Hadassah University Hospital and Hebrew University Medical

School, Jerusalem, Israel

Full list of author information is available at the end of the article
}

\section{$\triangle B M C$}

(c) The Author(s). 2021 Open Access This article is licensed under a Creative Commons Attribution 4.0 International License, which permits use, sharing, adaptation, distribution and reproduction in any medium or format, as long as you give appropriate credit to the original author(s) and the source, provide a link to the Creative Commons licence, and indicate if changes were made. The images or other third party material in this article are included in the article's Creative Commons licence, unless indicated otherwise in a credit line to the material. If material is not included in the article's Creative Commons licence and your intended use is not permitted by statutory regulation or exceeds the permitted use, you will need to obtain permission directly from the copyright holder. To view a copy of this licence, visit http://creativecommons.org/licenses/by/4.0/ The Creative Commons Public Domain Dedication waiver (http://creativecommons.org/publicdomain/zero/1.0/) applies to the data made available in this article, unless otherwise stated in a credit line to the data. 


\section{Background}

Multiple sclerosis (MS) is a classical inflammatory demyelinating disease of the central nervous system (CNS). Experimental autoimmune encephalomyelitis (EAE) is a complex condition that mimics the key pathological features of MS, which is characterized by interactions between a variety of immunopathological and neuropathological mechanisms, such as inflammation, demyelination, axonal loss, and gliosis. This model has been helpful for the development of new therapies for MS [1-4] and will also be applied in the present study.

Our previous work used the EAE model to demonstrate the novel anti-inflammatory effects of the nonneuronal cholinergic system in EAE and neuroinflammation [5-7]. The cholinergic system modulates interactions between the CNS and the immune system and plays a role in the modulation of various immune functions. This forms the basis of nerve-immune interactions, whereby the nervous system plays a part in controlling the magnitude and quality of immune responses. In our previous research, cholinesterase inhibitors (ChEIs) and nicotine $[5,6]$ were shown to attenuate the clinical symptoms of EAE and to inhibit T cell reactivity and cytokine production. These cholinergic effects were dependent on the activation of $\alpha 7$ nicotinic acetylcholine receptors ( $\mathrm{nAChRs)}$ on immune cells. Initially, $\alpha 7 \mathrm{nAChR}$ was identified as an anti-inflammatory target in macrophages [8, 9]; later, it was shown to be expressed and function in various immune cells, such as $\mathrm{T}$ cells [5], dendritic cells, and B cells [9]. Indeed, it has been demonstrated that nicotinic receptors in the periphery inhibit auto-reactive $\mathrm{T}$ cell proliferation and alter their cytokine profile [10]. In the CNS, nicotine exposure reduces the number of dendritic cells, infiltrating monocytes, and resident microglial cells, and downregulates the expression of MHC class II molecules [11]. Additionally, with regard to EAE, Godin et al. reported that the non-competitive $\mathrm{nAChR}$ antagonist mecamylamine and the silent agonist 1-ethyl-4-(3-(bromo)phenyl)piperazine (m-bromo PEP) reduced pro-inflammatory responses and ameliorated EAE [12]. All these findings indicate that therapeutic agents that target nAChRs may have potential for the treatment of neuroinflammatory diseases such as MS.

$\alpha 7$ nAChR has unique physiological and pharmacological properties including high permeability for calcium and sodium, and rapid and reversible desensitization [13]. In addition, $\alpha 7 \mathrm{nAChRs}$ are activated by acetylcholine (ACh) and selectively by choline, which is a precursor and breakdown product of ACh. New approaches for the therapeutic targeting and activation of $\alpha 7 \mathrm{nAChRs}$ have identified several $\alpha 7$-selective positive allosteric modulators (PAMs) that overcome the limitations of ligands that directly activate $\alpha 7 \mathrm{nAChRs}$
[14]. For example, GAT107 that was used in the current study, is a dual allosteric agonist and a positive allosteric modulator (ago-PAM) of $\alpha 7 \mathrm{nAChR}$ [15]. Activation of $\alpha 7$ nAChRs by GAT107 stimulates the antiinflammatory pathway of the immune cholinergic system and can modulate immune responses [16], and recently, Quadri et al. also showed that GAT107 directly caused opening of $\alpha 7 \mathrm{nAChR}$ channel [17]. This unique agonist was also shown to have long-lasting effects on receptor activity [16].

The cascade of events leading to CNS inflammatory lesions is initiated by CD4+T cells that are activated in the periphery towards myelin antigens. These encephalitogenic $\mathrm{T}$ cells then migrate to the $\mathrm{CNS}$, and upon additional activation with resident antigen-presenting cells (APC) such as microglia, astrocytes, and a subpopulation of dendritic cell, induce plaque formation [18]. The $\alpha 7$ nAChR is expressed by naïve T cells, as well as by macrophages. Its expression is augmented following immune activation. Nicotine and ACh could inhibit T cell proliferation in response to mitogen, by activation of $\alpha 7$ $\mathrm{nAChR}$ [19]. The $\alpha 7 \mathrm{nAChR}$ affect different immune cells including glial cells, which can participate in immune reaction. The various effects of the $\alpha 7 \mathrm{nAChR}$ on the different cell types are summarized in the review [9].

B cells, which are best known for their capacity to produce antibodies, also infiltrate MS lesions in the CNS. Some B cells produce antibodies against myelin antigens and, thus, can lead to demyelination and axonal damage [20]. Besides antibody production, the functions of $B$ cells in MS include antigen presentation, co-stimulation, and production of pro-inflammatory cytokines, such as IL-6, or anti-inflammatory cytokines such as IL-10 [21, 22].

In EAE, B cells have distinct pathogenic or regulatory functions that are dependent on the stage of the disease [23]. This is supported by findings in B cell-deficient mice, which exhibit an exacerbated disease course that is probably a result of the disruption of the regulatory functions of B cells and their capacity to produce IL-10 $[20,24,25]$. However, B cell depletion after EAE induction ameliorates disease severity due to the pathogenic role of memory $B$ cells, which facilitate $\mathrm{T}$ cell reactivation during later stages of the disease [26-29]. Recently, there is increasing interest in the significant role of $B$ cells in MS; therefore, we tested in the present study how the ago-PAM GAT107 influences B cell populations and their functions in EAE.

In the present study, we investigated the effects of the ago-PAM GAT107 on the cholinergic immune system in EAE mice. Our findings indicate that treatment with this specific agonist had beneficial effects on the clinical severity of EAE, inflammatory processes in the CNS, and the pattern of immune cell sub-populations. In addition 
to its immunomodulatory effects on the MS model animals, GAT107 demonstrated a direct effect on the cellular inflammatory responses of macrophages and human peripheral blood mononuclear cells (PBMCs). Therefore, our findings indicate that GAT107 has therapeutic potential in the treatment of inflammatory diseases of the CNS through activation of the cholinergic immune system.

\section{Methods}

Mice

Female C57BL/6 mice (7-8 weeks old) were purchased from Harlan Laboratories, Rehovot, Israel, and housed under specific pathogen-free conditions in the animal facility of the Hebrew University Medical School, Jerusalem, Israel, in accordance with the National Institutes of Health guidelines for the care and use of laboratory animals.

\section{EAE induction and clinical evaluation}

EAE was induced in 8-week-old female C57BL/6 mice by subcutaneous administration of $250 \mu \mathrm{g}$ of myelin oligodendrocyte glycoprotein $\left(\mathrm{MOG}_{35-55}\right)$ (synthesized by Sigma Laboratories, Israel) emulsified in complete Freund's adjuvant (CFA) containing $5 \mathrm{mg} / \mathrm{ml}$ heat-killed Mycobacterium tuberculosis. The $\mathrm{MOG}_{35-55}$ peptide was administered in the left paralumbar region. Immediately after the first injection and $48 \mathrm{~h}$ later, $200 \mathrm{ng}$ of the pertussis toxin (List Biological Industries, San Diego, CA, USA) was intraperitoneally (i.p.) administered as previously described [3]. All the animals were examined daily and evaluated for clinical signs of EAE. The clinical status of the mice was graded as follows: $0=$ no clinical disease, 1 = tail weakness, $2=$ hind limb weakness sufficient to impair righting, $3=$ single-limb plegia, $4=$ paraplegia with forelimb weakness, 5 = quadriplegia, and $6=$ death. According to the ethical requirements, mice that reached stage 4 were euthanized.

The clinical evaluation of the EAE mice was performed by a non-informed investigator; the division of the mice into the groups of the placebo or GAT 107 treatment was done in the same manner.

\section{GAT107 treatment}

GAT107 was dissolved in a mixture of ethanol, Emulphor-620 (Rhone-Poulenc Inc., Princeton, NJ, USA), and distilled water at a vol:vol:vol ratio of 1:1:18 [16]. GAT107 or placebo were intraperitoneally administered twice a day at a dose of $10 \mathrm{mg} / \mathrm{kg}$ [16], starting from the EAE induction day, for 8 consecutive days. Mice were followed clinically as described in the previous subsection.

\section{Evaluation of CNS pathology}

On the day of sacrifice, lumbar spinal cords, where inflammatory foci predominate in our model, were harvested, fixed in $4 \%$ paraformaldehyde, dehydrated, and embedded in paraffin. Longitudinal sections containing both gray and white matter, which cover the majority of the length of the spinal cord, were stained with hematoxylin-eosin as previously described [30]. Slides were evaluated under a light microscope (Axioplan-2; Zeiss), and inflammatory foci containing at least 20 perivascular mononuclear cells were counted in each section.

\section{Mouse lymphocyte proliferation assay}

Pooled lymph node cells (LNCs) were prepared from the inguinal, axillary, and mesenteric lymph nodes or from spleens derived from naive mice or from mice that had been subcutaneously inoculated 9 days earlier with the $\mathrm{MOG}_{35-55}$ peptide in CFA. The in vitro lymphocyte response was assayed in triplicate wells of 96-well flatbottom microtiter plates as previously described [31]. A total of $2 \times 10^{5}$ LNCs, suspended in $0.2 \mathrm{ml}$ RPMI supplemented with $5 \%$ fetal calf serum (FCS), were added to each well with or without $100 \mu \mathrm{g} / \mathrm{ml}$ of the $\mathrm{MOG}_{35-55}$ peptide. At $48 \mathrm{~h}$ after seeding, $1 \mu \mathrm{Ci}\left[\mathrm{H}^{3}\right]$ thymidine (Amersham Pharmacia Biotech, Amersham, Buckinghamshire, UK) was added to each well as a radioactive marker, and the plates were incubated for an additional $18 \mathrm{~h}$. The plates were then harvested with a semiautomated harvester onto a glass fiber filter, and radioactivity was assessed with a liquid scintillation assay.

\section{Cytokine secretion assay}

The culture media containing splenocytes or LNCs were incubated in the presence of $\mathrm{MOG}_{35-55}$, anti-CD3 antibody, ConcavalinA (ConA), or lipopolysaccharide (LPS). Supernatant was collected at different time points: at 24 $\mathrm{h}$ for the IFNY and IL-17 assay, and at $72 \mathrm{~h}$ for the IL-10 assay. The cytokine concentrations were determined with ELISA kits for each of the cytokines (Biolegend, San Diego, CA, USA).

\section{Flow cytometry analysis}

For leukocyte surface marker determination, pooled LNCs or splenocytes were obtained from mice (as described in the mouse lymphocyte proliferation assay). Cell suspensions were prepared as described previously [31]. For immune phenotyping, the following antibodies were used: anti-CD4 FITC, anti-CD8 FITC, anti-CCR5 PE, anti-B220 FITC, anti-CD11c PE, anti-MHC class II FITC, and anti-CD11b PE (all from eBioscience, San Diego, CA, USA). Stained cells were counted with a FACS Calibur flow cytometry kit (FC500, Beckman Coulter). 


\section{Quantitative real-time PCR}

Total RNA was prepared using a GeneJET RNA purification kit (Thermo Fisher Scientific), and cDNA was prepared from $1 \mu \mathrm{g}$ of total RNA with a $\mathrm{qScript}^{\mathrm{TM}}$ cDNA synthesis kit (Quanta Bio). The PCR reaction mixture contained $50 \mathrm{ng} \mathrm{cDNA}, 300 \mathrm{nM}$ of the appropriate forward and reverse primers (Sigmae Genosys Ltd., Cambridgeshire, UK), and $6 \mu \mathrm{l}$ of the master mix buffer containing nucleotides, Taq polymerase, and SYBR Green (SYBR Green fast mix ROX, Quanta bio) in a total volume of $10 \mu \mathrm{l}$. Gene amplification was carried out using the StepOnePlus ${ }^{\text {tu }}$ real-time PCR system (Thermo Fisher Scientific). The amplification protocol was as follows: $10 \mathrm{~min}$ at $95{ }^{\circ} \mathrm{C}$ followed by 40 cycles of a two-step loop $\left(20 \mathrm{~s}\right.$ at $95{ }^{\circ} \mathrm{C}$ and $1 \mathrm{~min}$ at $\left.60{ }^{\circ} \mathrm{C}\right)$. The results are expressed as relative quantification (RQ) values, that is, as the fold increase in gene expression in samples from $\mathrm{MOG}_{35-55}$-treated cells compared to the gene expression in control cells. The results for gene expression were normalized to the HPRT gene, as its expression did not change under the experimental conditions.

The following primers were used:

\section{HPRT}

Forward: 5' -TCCTCCTCAGACCGCTTTT-3' Reverse: 5'-CCTGGTTCATCATCGCTAATC-3'

2. GATA-3

Forward: 5'-GCAGAAAGCAAAATGTTTGCTTC-3' Reverse: 5'-GAGTCTGAATGGCTTATTCACAAA TG-3'

3. RORYt

Forward: 5' -CCCTGGTTCTCATCAATGC-3' Reverse: 5'-TCCAAATTGTATTGCAGATGTTC-3'

4. T-bet

Forward: 5' -CAGTTCATTGCAGTGACTGCCT AC-3'

Reverse: 5' -CAAAGTTCTCCCGGAATCCTTT-3'

5. FoxP3

Forward: 5' -AGAAGCTGGGAGCTAT-3'

Reverse: 5'-GCTACGCTGCAGCAAG-3'

6. TGF- $\beta$

Forward: 5' -TCAGACATTCGGGAAGCAGT-3'

Reverse: 5'-ACGCCAGGAATTGTTGCTAT-3'

7. BAFF

Forward: 5' -TGCTACTCGGCTGGCATCGC-3' Reverse: 5'-GCGCCGGCTCCGTTTCTCAT-3'

8. BAFF-R

Forward: 5' -GACCCTGGGTCTAGTGA-3' Reverse: 5' -GTAGGAGCTGAGGCATGAGG-3'

9. BCMA

Forward: 5' -ATCTTCTTGGGGCTGACCTT-3' Reverse: 5'-CTTTGAGGCTGGTCCTTCAG-3'

10. APRIL
Forward: 5' -CTGGAGGCCAGGGAGACAT-3'

Reverse: 5' -GCACGGTCAGGATCAGAAGG-3'

11. TACI

Forward: 5' -CTACTACACACTGGGGGTCT-3'

Reverse: 5'-CTCCTGAGTGGGAGAACTGC-3'

12. OPN

Forward: 5'-AGCAAGAAACTCTTCCAAGCAA-3'

Reverse: 5' -GTGAGATTCGTCAGATTCATCCG-3'

\section{ELISA for serum anti-MOG ${ }_{35-55}$ antibody}

The level of MOG-specific antibody during the course of EAE was measured using specific ELISA as previously described [3]. Individual wells in 96-well flat-bottom ELISA microplates (Nunc, Denmark) were coated with $100 \mu \mathrm{l}$ of $1 \mu \mathrm{g} / \mathrm{ml} \mathrm{MOG}_{35-55}$ in $0.17 \mathrm{M}$ borate coating buffer ( $\mathrm{pH} 8)$ and incubated overnight at $4{ }^{\circ} \mathrm{C}$. The plates were then blocked for $90 \mathrm{~min}$ at room temperature (RT) with phosphate-buffered saline (PBS) containing $1 \%(\mathrm{w} / \mathrm{v})$ bovine serum albumin (BSA). Next, the plates were washed with saline containing $0.05 \%$ Tween 20 and PBS, and $100 \mu \mathrm{l}$ of serum diluted to 1:200 or 1:100 in dilution buffer (PBS containing 1\% BSA and $0.05 \%$ Tween 20 ) was added to the plates. Serum from naive mice served as the negative control. The plates containing the serum solutions were then incubated overnight at $4{ }^{\circ} \mathrm{C}$ and washed (with saline containing $0.05 \%$ Tween 20 and PBS). Following this, they were incubated for $90 \mathrm{~min}$ at RT with $100 \mu \mathrm{l}$ of alkaline phosphatase-conjugated goat anti-mouse IgG (Fc specific) or anti-IgM ( $\mu$ chain specific) (Sigma, USA), diluted 1:35,000 in dilution buffer. The reaction product was visualized using $p$-nitrophenyl phosphate $(1 \mathrm{mg} / \mathrm{ml}$; Sigma, USA) in $1 \mathrm{M}$ diethanolamine buffer ( $\mathrm{pH}$ 9.8) containing $0.5 \mathrm{mM} \mathrm{MgCl} 2$ and incubated for $50 \mathrm{~min}$ at RT. The reaction was terminated by the addition of $30 \mu \mathrm{l}$ of $3 \mathrm{~N} \mathrm{NaOH}$. Absorbance at $405 \mathrm{~nm}$ was measured in a micro-ELISA reader.

\section{Direct effect of GAT107 on the inflammatory responses of murine macrophage RAW cells}

RAW 264.7 cells, a line of murine macrophage adherent cells, were grown in complete culture media consisting of RPMI 1650 supplemented with 10\% fetal bovine serum, $1 \%$ glutamine, and $1 \%$ PenStrep. All experiments with the cells were conducted in a sterile laminar hood. On the first day of each experiment, $1.5 \times 10^{6}$ cells were plated in 6-well dishes containing $3 \mathrm{ml}$ of complete culture media, as previously described [32]. The following day, the medium was changed, and ACh $(100 \mu \mathrm{M})$, GAT107 $(10 \mu \mathrm{M})$, and the nicotinic antagonist methyllycaconitine (MLA) (10 nM) were added to the wells and incubated at $37{ }^{\circ} \mathrm{C}$ in a $5 \% \mathrm{CO}_{2}$ atmosphere for $0.5 \mathrm{~h}$. Subsequently, LPS $(25 \mu \mathrm{g} / \mathrm{ml})$ was added to the wells and incubated for an additional $9 \mathrm{~h}$ under the same 
conditions. Supernatants were collected at the end of incubation and frozen at $-80{ }^{\circ} \mathrm{C}$ until the IL- 6 concentration was determined with the ELISA kit (Biolegend, San Diego, CA, USA).

\section{Effects of GAT107 and ACh on human PBMCs}

Peripheral blood samples from 24 healthy donors and 32 MS patients were collected in EDTA tubes (Vacuette; Greiner Bio-one). PBMCs were isolated by Ficoll-Hypaque density gradient centrifugation and re-suspended in complete culture media consisting of RPMI 1640 medium supplemented with $5 \%$ fetal calf serum(FCS), penicillin + streptomycin (100 i.u./ml), MEM nonessential amino acids (1:100), pyruvate $(1 \mathrm{mM})$, L-glutamine solution $(2 \mathrm{mM})$, and $\beta$-mercaptho-ethanol (3 $\mathrm{nM})$. The isolated PBMCs $\left(1 \times 10^{6}\right)$ were immediately placed in 24-well plates in a volume of $0.5 \mathrm{ml}$ of complete culture medium. ACh $(100 \mu \mathrm{M})$ and GAT107 $(10 \mu \mathrm{M})$ were added to the wells, and the plates were incubated at $37{ }^{\circ} \mathrm{C}$ in a $5 \% \mathrm{CO}_{2}$ atmosphere for $0.5 \mathrm{~h}$. Subsequently, ConA $(5 \mu \mathrm{g} / \mathrm{ml})$ was added to the wells and the plate was incubated for an additional $24 \mathrm{~h}$ in the same conditions. Supernatants were collected at the end of incubation and frozen at $-80{ }^{\circ} \mathrm{C}$ until assay. The IL17 and IL-6 concentrations were determined with the ELISA kit (Biolegend, San Diego, CA, USA). The HD and MS characteristics are presented in Table 1.

The present study was approved by the local Helsinki Committee and the Israeli Institutional Review Board (approval number HMO0298-17).

\section{Statistical analysis}

The data were analyzed using Student's $t$-test and oneway ANOVA, according to Dunnett, and the Fisher exact test. $p<0.05$ was considered to indicate statistical significance.

\section{Results}

\section{Amelioration of EAE with GAT107 treatment}

To assess the influence of $\alpha 7 \mathrm{nAChR}$ activation during neuroinflammation in EAE, we used the ago-PAM G AT107. EAE model mice were divided into two groups: one group was treated with placebo, while the second group was treated with GAT107. The treatment

Table 1 Epidemiological and clinical characteristic of the MS patients and the healthy donors

\begin{tabular}{lll}
\hline & Healthy donors & MS patients \\
\hline $\boldsymbol{n}$ & 24 & 32 \\
Female/male & $19 / 5$ & $23 / 9$ \\
Age (mean \pm SE) & $36.4 \pm 3.2$ & $40.1 \pm 2.5$ \\
Disease duration (mean \pm SE) & -- & $7.4 \pm 1.1$ \\
EDSS (mean \pm SE) & -- & $2.2 \pm 0.3$ \\
\hline
\end{tabular}

consisted of a total of 16 intraperitoneal injections, starting from the day of EAE induction, for 8 days, twice a day, at a dose of $10 \mathrm{mg} / \mathrm{kg}$ [16]. As shown in Fig. 1 and Table 2, treatment with GAT107 remarkably reduced mean disease severity (which was the average daily clinical score) by $78 \%$ compared with the placebo group ( $p$ $<0.001)$. Similarly, the cumulative score, which was calculated as the number of days that the animal was sick multiplied by the clinical score, was reduced by $76 \%$ with GAT107 treatment $(p<0.001)$. Additionally, the max score, which indicated the average maximum clinical score for each mouse, was reduced by $70 \%(p<0.001)$, and the day of onset (the average of the first day of clinical symptom appearance) was delayed by 3 days in the GAT107-treated group $(p<0.05)$ (Table 2). These effects persisted long after GAT107 administration was discontinued.

Mice were intraperitoneally administered GAT107 or saline (control group) at a dose of $10 \mathrm{mg} / \mathrm{kg}$ twice a day for 8 consecutive days. Mean severity is the average of the daily clinical score of each group. The cumulative score is calculated as the number of days that the animal was sick multiplied by the clinical score. The max score indicates the average maximum clinical score for each mouse in each group. The day of onset indicates an average for the first day of clinical symptoms appearance of each group (" $\left.p<0.05,{ }^{* * *} p<0.001\right)$

\section{Inhibition of CNS inflammation by GAT107}

The significant difference in clinical disease score between the GAT107-treated and placebo-treated mice was confirmed by the findings from histological analysis of spinal cord tissue resected at day 30 of disease induction. In the placebo-treated group, pronounced perivascular, and meningeal infiltration was observed (Fig. 2), whereas the extent of inflammation was much lesser in the GAT107-treated group. Indeed, GAT107 treatment resulted in an $80 \%$ decrease in the number of inflammatory foci compared with the placebo-treated group $(p<$ 0.001) (Fig. 2).

\section{Inhibitory effect of GAT107 on MOG-specific T cell proliferation and pro-inflammatory cytokine production} To assess the influence of GAT107 on CNS inflammation, we treated MOG-induced EAE mice from the day of induction with GAT107 or placebo. On day 9 after treatment initiation, the mice were sacrificed. Pooled LNCs or splenocytes from both groups were restimulated ex vivo with the encephalitogenic $\mathrm{MOG}_{35-55}$ peptide (Fig. 3a), with the mitogen ConA, LPS, or antiCD3 antibody (Fig. 3b), lymphocyte proliferation and cytokine secretion were assessed (Fig. $3 \mathrm{a}-\mathrm{c}$ ). LNC proliferation in GAT107-treated mice was reduced by $27 \%$ on re-stimulation with $\mathrm{MOG}_{35-55}$ (Fig. 3a). Similarly, in 


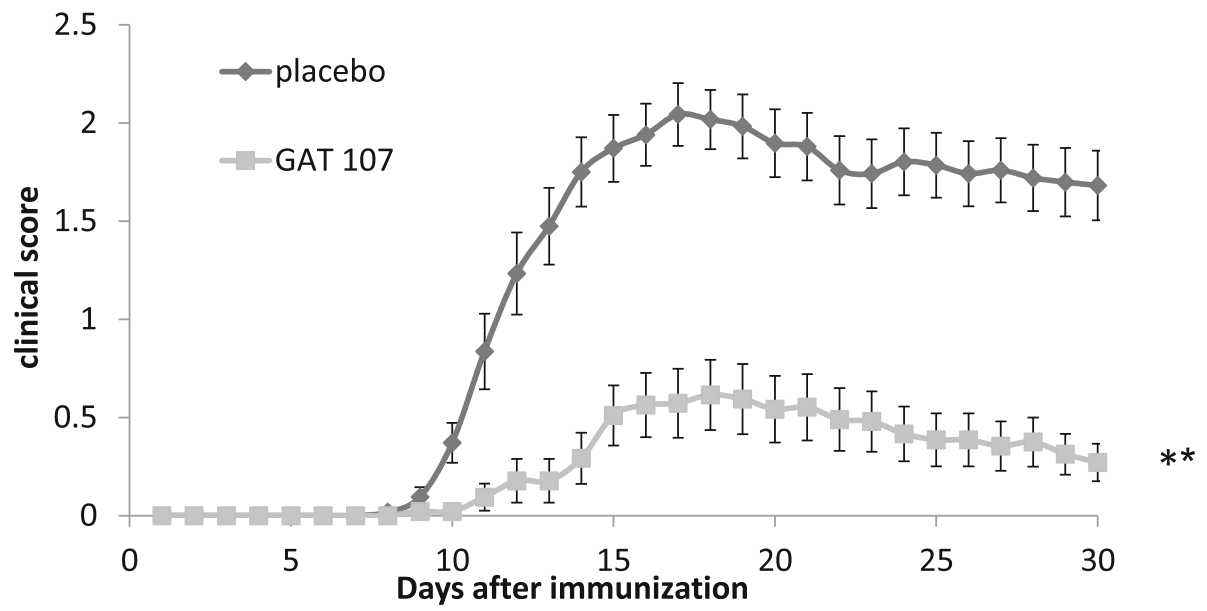

Fig. 1 Amelioration of the clinical course of EAE on treatment with the ago-PAM GAT107. EAE was induced in wild-type (WT) mice by immunization with myelin oligodendrocyte glycoprotein (MOG) $35-55$. The animals were given either placebo or GAT107 (10 mg/kg) twice daily by intraperitoneal injection. The results are expressed as the mean clinical score \pm standard error (SE) of data from four separate experiments $(n=29$ in the placebo group and $n=24$ in GAT107-treated group) $\left({ }^{* *} p<0.001\right)$

presence of the anti-CD3 antibody, ConA, and LPS, LNC proliferation was reduced by $55 \%, 49 \%$, and $41 \%$ respectively (Fig. 3b). The reduction was accompanied by $94 \%, 80 \%$, and $60 \%$ decrease in the secretion of proinflammatory cytokines IL-17, INF $\gamma$, and IL-6 respectively (Fig. 3c). In addition, a 2.8-fold increase in the secretion of the anti-inflammatory cytokine IL-10 was also observed (Fig. 3c).

\section{Effect of GAT107 on the expression of immune cells}

Next, we tested the effects of GAT107 on immune cell populations. The phenotype of splenocytes was characterized by FACS analysis on post-immunization day 9 . Interestingly, there was a significant decrease in the expression of CD11b- (macrophages), CD11c- (dendritic cells), and CCR5-positive cells (by 37\%, 31\%, and 45\%, respectively) in the GAT107-treated mice. However, there was no significant difference in the number of CD4-, CD8-, and MHC class II-positive cells between the placebo-treated and GAT107-treated mice (Fig. 3d).

To further examine the in vivo effects of GAT107 on immune cell differentiation and proliferation, we examined the expression of several transcription factors (TFs) and TGF $\beta$, which can serve as indicators for Th1, Th2, and Th17 as well as Treg maturation. As shown in Fig. 4, GAT107 resulted in a significant increase in the levels of T-bet (a TF for Th1), by 2-fold, and GATA-3 (a TF for Th2), by 1.8-fold. Similarly, it also resulted in an increase in IL-10. However, the expression of ROR- $\gamma \mathrm{t}$, a TF of Th17, did not change following GAT107 treatment, although a significant reduction was observed in IL-17 secretion. In addition, we found an increase in the expression of foxp3 and TGF $\beta$, the TFs associated with regulatory $\mathrm{T}$ cells, by 2.9 -fold and 1.7 -fold, respectively.

\section{Effect of GAT107 on serum anti-MOG $35-55$ antibodies and $B$ cell markers}

Recently, the significant role of B cells in MS has come under the limelight. Therefore, we investigated the effect of GAT107 on anti-MOG antibodies and B cell markers in the EAE mice. B220, a B cell marker that represents a subset of mouse CD45 isoforms, is predominantly expressed on all B lymphocytes, including pro-mature and activated B cells, and was used as a marker of B cells. GAT107-treated mice showed a significant (9.7\%) decrease in B220 expression at post-immunization day 9 (Fig. 5a). Similar results were also found at post-immunization day 30 (data not shown). In addition, the level of serum anti$\mathrm{MOG}_{35-55}$ antibodies during the chronic phase of the disease (post-immunization day 30 ) showed a $33 \%$ reduction following treatment (Fig. 5b). This finding is consistent with the reduction in B cells, which play a role in antibody production.

To further examine the effects of GAT107 on the regulation of antibody production and B cell survival, we

Table 2 Influence of treatment with GAT107 on the clinical parameters of EAE

\begin{tabular}{lllll}
\hline & Mean severity & Cumulative score & Max score & Day of onset \\
\hline Placebo & $1.8 \pm 0.15$ & $33.8 \pm 2.9$ & $2.25 \pm 0.14$ & $11.2 \pm 0.5$ \\
GAT107 & $0.4 \pm 0.12^{* *}$ & $8.1 \pm 2.4^{* *}$ & $0.68 \pm 0.18^{* *}$ & $14.2 \pm 0.6^{*}$ \\
\hline
\end{tabular}

${ }^{*} p<0.05,{ }^{* *} p<0.001$ 
A

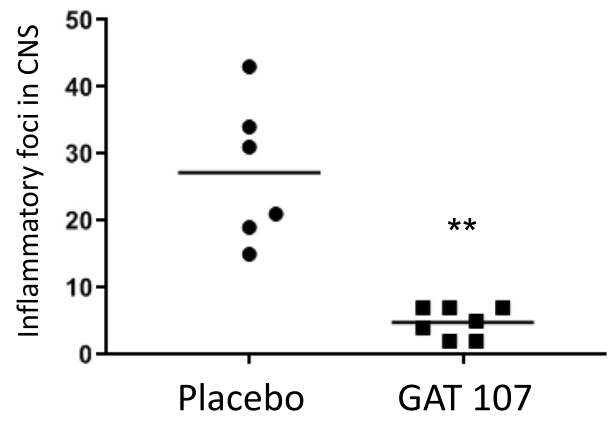

B

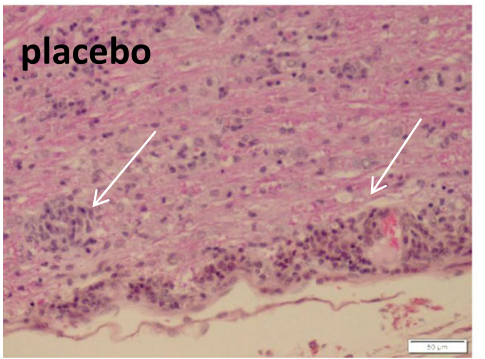

C

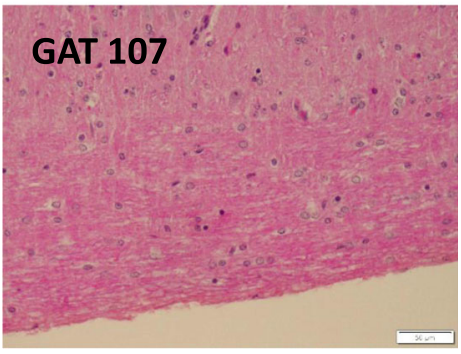

Fig. 2 Neuropathological features of spinal cords in EAE mice treated with GAT107. Spinal cords of mice from the placebo- and GAT107-treated groups were removed at day 30 after EAE induction. a Treatment with GAT107 (10 mg/day) for 8 days improved CNS inflammation and reduced the number of EAE lesions. Representative images (with hematoxylin and eosin staining) at $\times 20$ magnification are shown for the $\mathbf{b}$ placebo- and c GAT107-treated cells. The arrows indicate the foci ( $n=6$ in the placebo group and $n=7$ in GAT107-treated group) $\left({ }^{* *} p<0.001\right)$

analyzed the expression of members of the BAFF family. Apart from BAFF, the family includes three receptors for BAFF: BAFF-receptor (BAFF-R), B cell maturation antigen (BCMA), and transmembrane activator and calcium modulator and cyclophilin ligand interactor (TACI). Two of these three receptors share the ligand APRIL (a proliferation-inducing ligand). As shown in Fig. 5c, the expression of BAFF-R, BCMA, and TACI did not significantly change in GAT107-treated mice; however, the expression of APRIL and BAFF was notably reduced by $54 \%$ and $68 \%$, respectively. The reduction in APRIL and BAFF is consistent with the lower level of $\mathrm{MOG}_{35-55}$ antibodies produced and the reduction in the number of $\mathrm{B}$ cells and, thus, represents a less severe manifestation of the disease in the GAT107-treated mice.

Subsequently, we investigated the expression of osteopontin (OPN), which is produced by a variety of cell types, including $\mathrm{B}$ and $\mathrm{T}$ cells, macrophages, neutrophils, dendritic cells, bone cells (osteoblasts and osteocytes), and neurons [33]. As expected in less severe disease, OPN expression was significantly reduced (by $47 \%$ ) in the GAT107-treated mice (Fig. 5c).

\section{Direct activation of $\alpha 7$ nicotinic AChRs by GAT107}

To examine whether GAT107 directly affects the immune cholinergic system, we examined its effect on RAW264.7, a macrophages cell line, and PBMCs from healthy donors (HDs) and MS patients. RAW264.7 cells were stimulated by LPS and incubated with agonists and antagonists of $\alpha 7 \mathrm{nAChR}$ (as described in the "Methods"), and the effects on IL-6 secretion were examined. As shown in Fig. 6, following LPS stimulation, ACh resulted in a 40\% decrease in IL-6 secretion and GAT107 resulted in a $46 \%$ decrease in IL-6 secretion (Fig. 6a). Treatment of the cells with the $\alpha 7 \mathrm{nAChR}$ antagonist MLA, along with GAT107 and LPS, eliminated the anti-inflammatory effects of GAT107 (Fig. 6b). These results demonstrate that GAT107 affects cytokine release via $\alpha 7 \mathrm{nAChR}$ activation.

PBMCs from HDs and MS patients were activated with ConA and incubated with GAT107 or ACh (as described in the "Methods"), and their effects on the secretion of the pro-inflammatory cytokines IL-6 and IL-17 were examined. As shown in Fig. 7, GAT107 caused a significant reduction in the secretion of both IL-6 and 


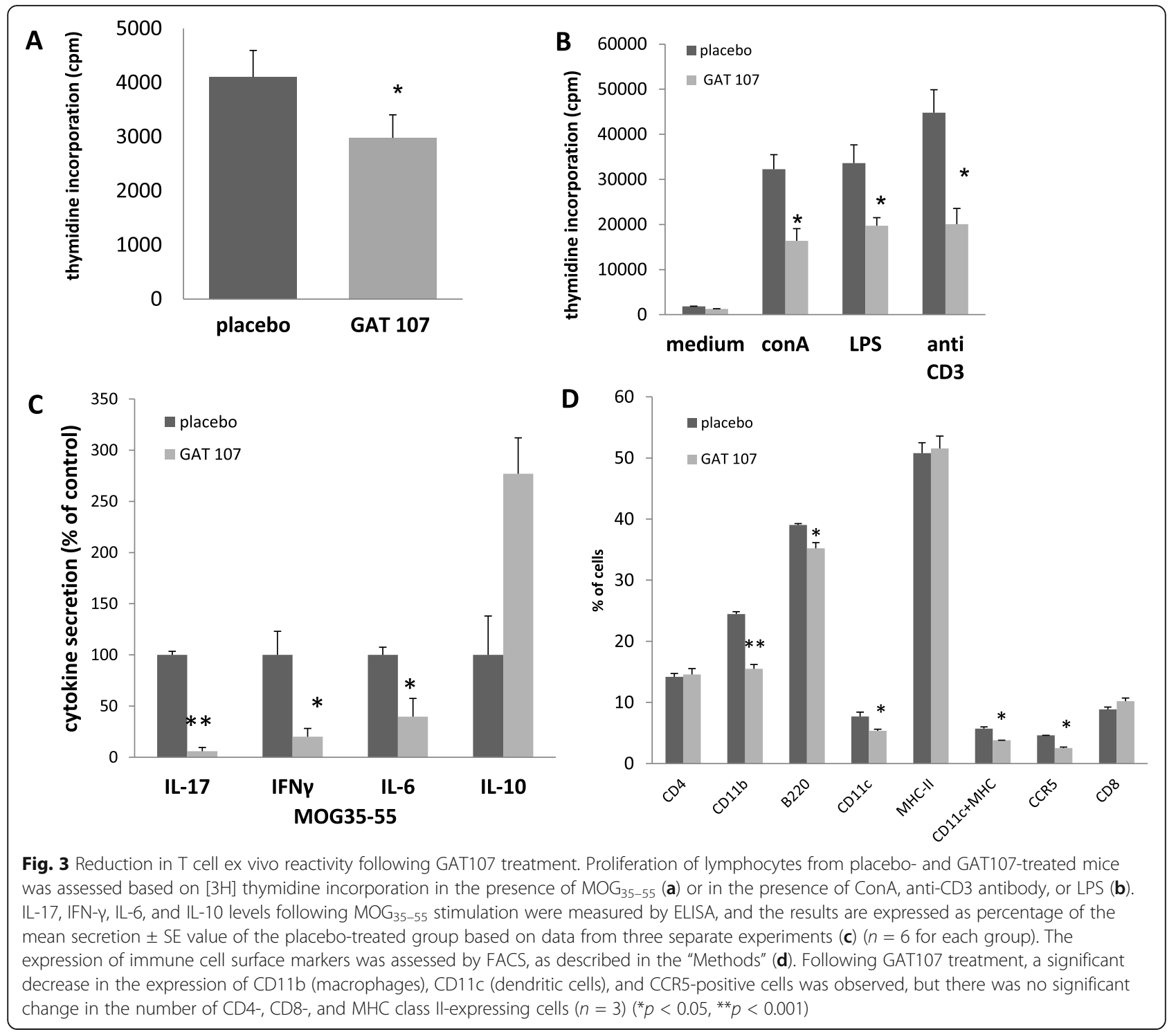

IL-17: IL-17 secretion was decreased by $11 \%$ in HDs and $18 \%$ in MS patients, and a similar decrease was observed after treatment with ACh (7\% in HDs and 13\% in MS patients). Additionally, GAT107 resulted in a 12\% (HDs) and $18 \%$ (MS patients) decrease in IL-6 secretion, and ACh resulted in a $14 \%$ (HDs) and $12 \%$ (MS patients) decrease in IL-6 secretion. Treatment of GAT107- and ConA-treated cells with MLA reversed the effect of GAT107 on cytokine production (data not shown). We noticed that the effects of the cholinergic agonist on cytokine release in MS patients (Fig. 7c, d) showed higher variability than its effects in HDs (Fig. 7a, b).

\section{Discussion}

The present study further supports the prominent involvement of the immune cholinergic system in EAE through the suppressive effects of GAT107, a dual allosteric agonist and positive allosteric modulator of $\alpha 7$ $\mathrm{nAChR}$, on the clinical symptoms and pathological features of EAE.

In the present study, we showed that on GAT107 treatment of EAE mice, the disease severity was significantly reduced by $78 \%$ and the average time to disease onset was significantly delayed. Our results are in agreement with previous results which showed that similar cholinergic stimulants, such as rivastigmine (ACh esterase inhibitor) [7] and EN101 (ACh esterase anti-sense molecule), activated the antiinflammatory system and, subsequently, improved EAE symptoms [6, 7]. Additionally, in this study, the neuropathological findings in the mice were consistent with the clinical severity scores and indicated that 

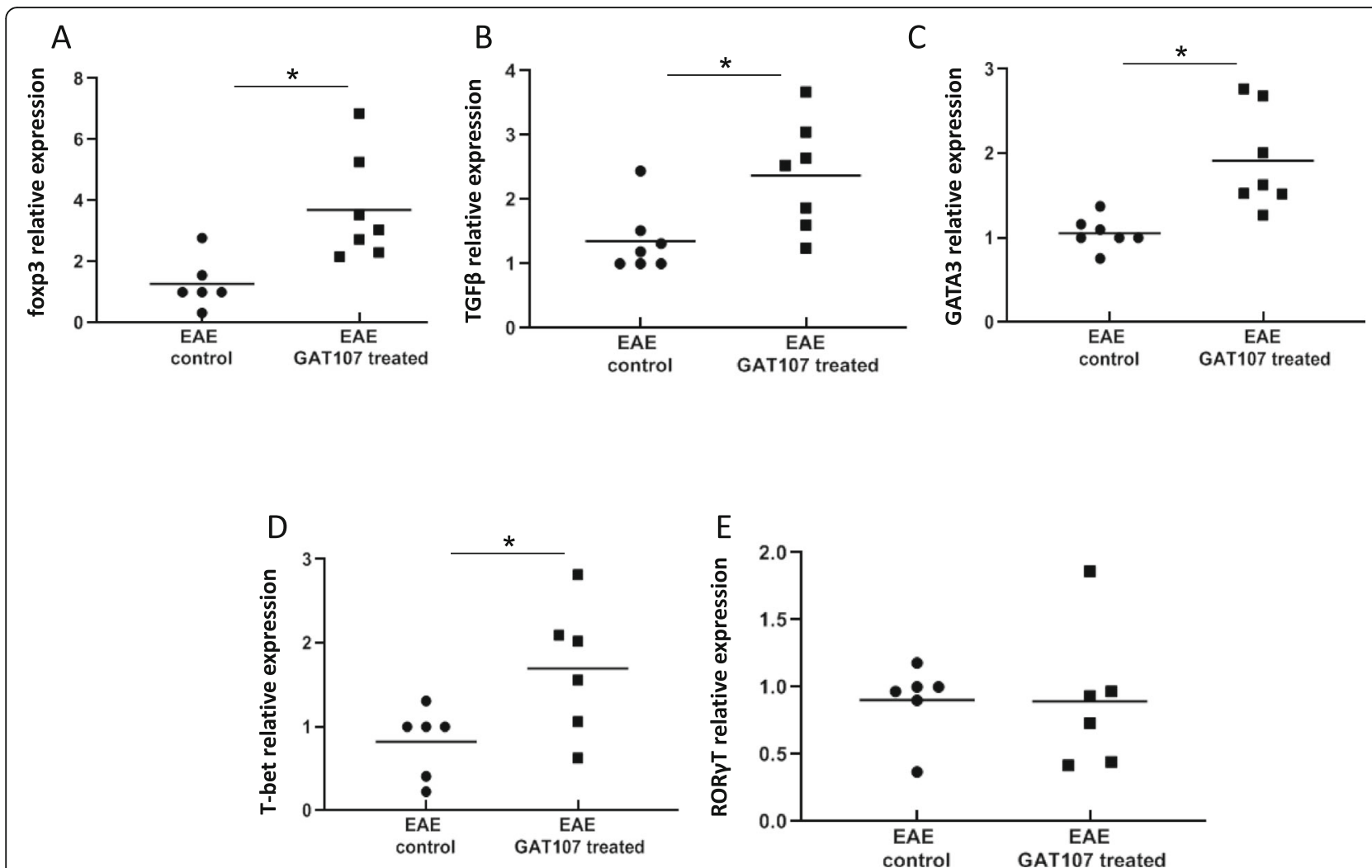

Fig. 4 mRNA expression levels of foxp3, TGFß, GATA3, T-bet, and RORyt following GAT107 treatment. Mice were treated with GAT107 (10 mg/ day, i.p.) for 8 days from the day of EAE induction. One day later, pooled lymphocytes were obtained and activated with $M_{0} O_{35-55}$ as described in the "Methods". mRNA levels of foxp3, TGF $\beta$, GATA3, T-bet, and RORyt were assessed by RT-PCR. The results are expressed as mean relative quantification value \pm SE of three separate experiments $\left(n=6-7\right.$ in each group) $\left({ }^{*} p<0.05\right)$

treatment with GAT107 resulted in a significant reduction in CNS neuroinflammation.

In the present study, the ameliorative effects of GAT107 were found to last for many days after treatment termination. Thus, GAT107 is likely to affect an initial stage in the cascade of events leading to CNS damage. Specifically, GAT107 may inhibit the proliferation of encephalitogenic T cells. As MS and EAE are autoimmune inflammatory diseases in which cytokines are extensively involved, accordingly, in this study, we found that Th1 and Th17 cytokines, which play a role in the induction of CNS inflammation and demyelination and in the pathogenesis of EAE and MS $[1,2,5]$, were markedly reduced by GAT107 treatment. In addition, the secretion of the anti-inflammatory cytokine IL-10 was increased. Thus, our findings support the notion that GAT107 acts on encephalitogenic cells in EAE and may, therefore, have a similar effect in other diseases that involve inflammation of the CNS.

In the present study, GAT107 treatment resulted in an increase in the level of GATA-3, which is involved in $\mathrm{Th}_{2}$ transcription. Unexpectedly, the treatment resulted in an increase in the transcription of T-bet, while Th1 cytokine secretion was reduced. Similarly, the Th17related TF ROR- $\gamma$ T was unaffected, despite the decrease in the production of Th17-related cytokines. Accordingly, a previous study from our laboratory also showed that treatment with nicotine did not affect ROR- $\gamma \mathrm{T}$ expression but reduced the secretion of Th17-related cytokines [5]. Based on these findings, it is possible that GAT107 treatment influenced effector Th17 and Th1 cells but not their differentiation/maturation.

Upon studying the effects of GAT107 on specific cell types, we found a reduction in the number of macrophages $(\mathrm{CD} 11 \mathrm{~b}+$ cells and $\mathrm{CD} 11 \mathrm{c}+$ cells). Macrophage activation results in the release of a range of proinflammatory cytokines and chemokines that contribute significantly to the expansion of the inflammatory response and associated tissue damage [34, 35].

In our study, we found a reduction in CCR5 expression following GAT107 treatment. This finding is in agreement with a previously reported study that CCR5 is involved in immune cell migration and cytokine release in the CNS [3]. Moreover, Gu et al. [36] reported that $\mathrm{CCR}^{-1-}$ mice develop less severe EAE than WT mice. Additionally, they reported that patients with MS exhibit 

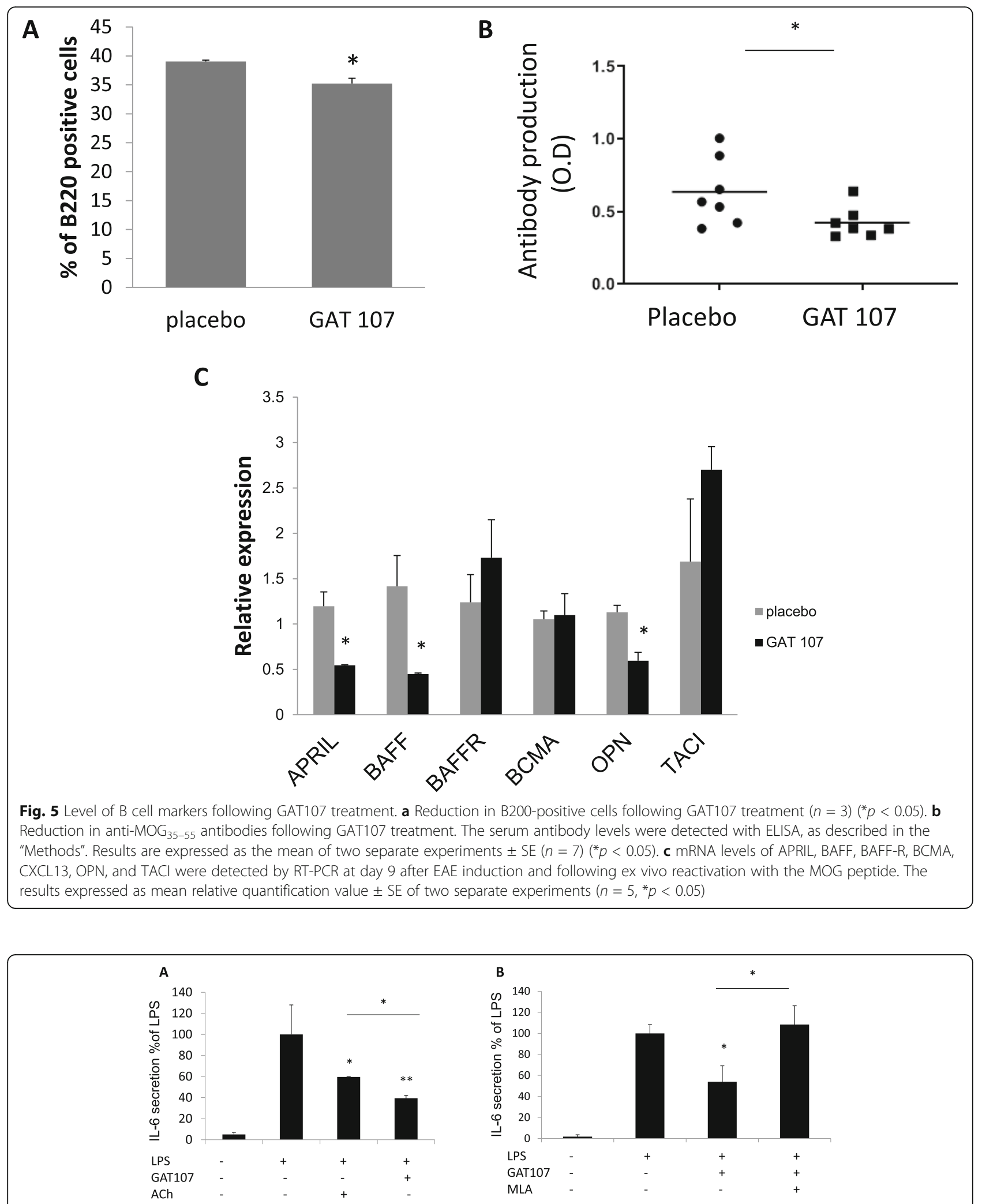

Fig. 6 Suppressive effect of GAT107 on inflammatory cytokine release from RAW267.4 cells. IL-6 production was measured in RAW267.4 cells stimulated with LPS $(25 \mu \mathrm{g} / \mathrm{ml})$ with and without a7 nAChR-targeting drugs. a Effects of ACh $(100 \mu \mathrm{M})$ and GAT107 $(10 \mu \mathrm{M})$ on LPS-dependent IL-6 release. b MLA $(10 \mathrm{nM})$ antagonizes the effects of GAT107 $(10 \mu \mathrm{M})$ on LPS-dependent IL-6 release $(n=4$ biological replicates, two technical replicates each) $\left(^{*} p<0.05,{ }^{* *} p<0.01\right)$ 

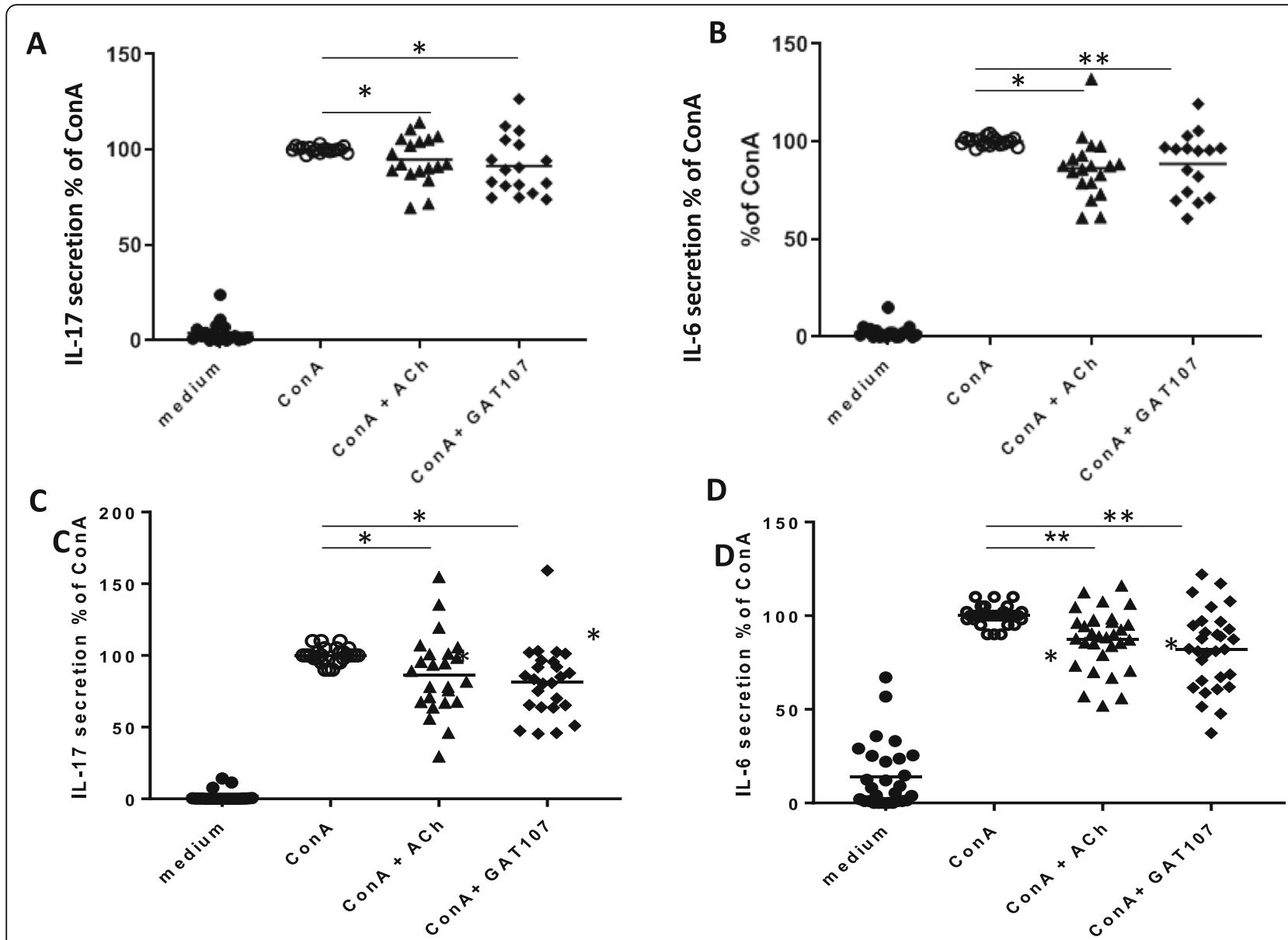

Fig. 7 Suppressive effect of GAT107 on inflammatory cytokine release from PBMCs from HDs and MS patients. PBMCs were purified from samples from human donors, including healthy donors $(\mathbf{a}, \mathbf{b})$ and MS patients $(\mathbf{c}, \mathbf{d})$, and stimulated with ConA (5 $\mu \mathrm{g} / \mathrm{ml})$ with and without ACh (100 $\mu \mathrm{M})$ or GAT107 $(10 \mu \mathrm{M})$ for $24 \mathrm{~h}$. $(\mathbf{a}+\mathbf{c})$ IL-17 and $(\mathbf{b}+\mathbf{d})$ IL-6 secretion were detected by ELISA $(n=17-19)\left({ }^{*} p<0.05\right)$

a higher percentage of circulating CCR5+ cells than control patients, and an increase in the number of these cells is associated with disease severity. These findings indicate that GAT107 action involves inhibition of T cell response, also via decrease number of CCR5+ cells. However, these findings do not imply whether the inhibition results from the reduction in the exit of those cells from the spleen or whether the treatment affect the survival and proliferation of those cells.

Tregs play a pivotal role in EAE and autoimmunity [31]. In this study, GAT107 resulted in a significant increase in the expression of foxp3 mRNA, which is a Treg marker. This finding was accompanied with an increase in the expression of TGF $\beta$, which also is associated with Treg maturation.

However, we have not tested the expression of these markers in the CNS, nor the amount of $\mathrm{T}$ regulatory cells in the CNS. These experiments are planned to be performed in the future to further substantiate the effects of GAT107, and whether it is due to exit of these cells from spleen or whether the treatment affects the survival and proliferation of these cells.

Recent study in a mouse pulmonary infection with Pseudomonas aeruginosa model show that activation of $\alpha 7$ nAChRs with GAT107, decreased the bacterial burden, and improved macrophage functions [37]. Thus, we can assume that although that GAT107 has suppressive effects on myeloid populations in the spleen, GAT107 administration is not likely to affect susceptibility to other infectious.

Even though there is much evidence that EAE progression (or its initiation) is dependent on the activity of $\mathrm{T}$ cells, there is also accumulating evidence for the contribution of B cells, plasma cells, and their secreted products in the pathogenesis of EAE [38, 39]. In addition, the pathology of MS suggests the involvement of B cells in the disease course: Areas of active demyelination point to the direct interaction of myelin-specific antibodies with myelin and macrophages [40]. These findings indicate that antibody involvement is one of the pathological 
pathways responsible for demyelination. In the present study, the levels of anti-MOG antibodies were reduced following GAT107 treatment. This may, therefore, be one of the mechanisms involved in the reduction of axonal damage and, therefore, in the amelioration of EAE. This reduction was accompanied with a decrease in the expression of the B cell marker B220. Therefore, the level of BAFF, APRIL, and OPN, which are associated with $B$ cell survival and function, was examined in this study. BAFF is a potent survival factor for B cells and plays an essential role in the preservation and maturation of peripheral B cells $[41,42]$. BAFF expression was decreased after GAT107 treatment in this study, and this may also explain the decrease in the percentage of $\mathrm{B}$ cells and the lower levels of anti-MOG $35-55$ antibodies. Thangarajh et al., reported that MS patients have a higher number of APRIL-positive cells in their brain than HDs [43]. Moreover, according to Agah et al., a higher OPN level in the CSF of MS patients is associated with more active and more severe disease [44]. These findings are in accordance with the reduction in APRIL and OPN expression observed in this study and may be correlated with reduced EAE severity. Overall, they confirm the role of B cells in the anti-inflammatory mechanisms effected by GAT107 in EAE.

In the present study, in vitro direct interaction of the $\alpha 7$ agonist with immune cells (murine macrophage RAW264.7 cells and PBMCs from human donors) resulted in a significant decrease in the pro-inflammatory cytokines IL-6 and IL-17 (in PBMCs), and ACh directly inhibited the production of these cytokines. Additionally, the specific $\alpha 7$ antagonist MLA reversed the antiinflammatory effects of GAT107 and ACh. In agreement with our findings, it has been shown that treatment with GAT107, which is specific to the $\alpha 7$ nicotinic receptor, activates the anti-inflammatory pathway in immune cells $[8,9,35]$. These results are also consistent with the findings of Bagdas et al., who showed that the antiinflammatory effects of cholinergic agonists are mediated by $\alpha 7 \mathrm{nAChR}$ in another animal model, inflammatory and neuropathic pain [16]. Altogether, these findings confirm that GAT107 promotes the anti-inflammatory pathway via a direct effect on $\alpha 7 \mathrm{nAChRs}$.

Our previous studies as well as the works of others [5, $11,32,45,46]$ show that $\alpha 7$ nAChRs play an important role in the modulation of inflammatory processes via the cholinergic anti-inflammatory pathway. This pathway has been implicated in the neuroinflammation in MS [11, 45], and recently, we reported [32] that following immunological activation, $\alpha 7 \mathrm{nAChR}$ expression is higher in MS patients than in healthy donors. Our current data further support the ability of $\alpha 7 \mathrm{nAChRs}$ to respond to cholinergic agents both in MS and in healthy donors.

\section{Conclusion}

The results presented in our study highlight the widespread immunomodulatory effects of the cholinergic anti-inflammatory pathway and the ability of the $\alpha 7$ nAChR-specific ago-PAM GAT107 to affect immunological processes. GAT107 treatment ameliorated EAE and modulated the cytokine pattern to an antiinflammatory one. Moreover, GAT107 treatment affected multiple immune cell types, namely, $\mathrm{T}$ cells, B cells, and macrophages. Thus, $\alpha 7 \mathrm{nAChR}$ activation by this allosteric molecule has persistent widespread therapeutic effect on the immune response and, therefore, may have potential for the therapeutic management of inflammatory autoimmune diseases.

\section{Abbreviations}

BBB: Blood-brain barrier; CFA: Complete Freund's adjuvant; CNS: Central nervous system; EAE: Experimental autoimmune encephalomyelitis; FCS: Fetal calf serum; INF: Interferon; IL: Interleukin; LNC: Lymph node cell; MOG: Myelin oligodendrocyte glycoprotein; MS: Multiple sclerosis; nAChR: Nicotinic acetylcholine receptor; ago-PAM: Allosteric agonist and positive allosteric modulator; PBMCs: Peripheral blood mononuclear cells; BCMA: B cell maturation antigen; TACl: Transmembrane activator and calcium modulator and cyclophilin ligand interactor; APRIL: A proliferation-inducing ligand; BAFF: B cell activating factor; BAFF-R: B cell activating factor receptor; OPN: Osteopontin; Ach: Acetylcholine; MLA: Methyllycaconitine

\section{Acknowledgements}

We thank Mrs. Camille Sicsic for her skillful assistance.

\section{Authors' contributions}

MT, MO, BK, and BDY, performed the animal and cell culture studies. MT, TB, and $M T$ were involved in writing the manuscript. MT, TB, MT, and VDA were involved in planning the study experiments. GAT designed and synthesized GAT 107. All authors approved the final manuscript.

\section{Funding}

Not applicable

Availability of data and materials

Data will be given upon request from the co-responding authors.

\section{Declarations}

\section{Ethics approval and consent to participate}

This study was approved by the ethics committee of Hebrew University, National Institutes for Health (approval number OPRR-A01-5011, MD1413867-5).

The studies on PBMCs were approved by the local Helsinki Committee and the Israeli Institutional Review Board (approval number HMO0298-17).

\section{Consent for publication}

Not applicable

\section{Competing interests}

The authors declare that they have no competing interests.

\section{Author details}

'Department of Neurology, The Agnes Ginges Center for Human Neurogenetics, Hadassah University Hospital and Hebrew University Medical School, Jerusalem, Israel. ${ }^{2}$ Department of Medical Neurobiology, Hebrew University—Hadassah Medical School, Jerusalem, Israel. ${ }^{3}$ Pharmaceutical Science, Bouve College of Health Science, Northeastern University, Boston, USA. 
Received: 20 December 2020 Accepted: 3 April 2021

\section{Published online: 26 April 2021}

\section{References}

1. Steinman L, Zamvil SS. How to successfully apply animal studies in experimental allergic encephalomyelitis to research on multiple sclerosis. Ann Neurol. 2006;60(1):12-21. https://doi.org/10.1002/ana.20913.

2. Constantinescu CS, Faroogi N, O'Brien K, Gran B. Experimental autoimmune encephalomyelitis (EAE) as a model for multiple sclerosis (MS). Br J Pharmacol. 2011; 164(4):1079-106. https:/doi.org/10.1111/j.1476-5381.2011.01302.x.

3. Irony-Tur-Sinai M, Grigoriadis N, Lourbopoulos A, Pinto-Maaravi F, Abramsky $\mathrm{O}$, Brenner T. Amelioration of autoimmune neuroinflammation by recombinant human alpha-fetoprotein. Exp Neurol. 2006;198(1):136-44. https://doi.org/10.1016/j.expneurol.2005.11.012.

4. Gur-Wahnon D, Mizrachi T, Maaravi-Pinto FY, Lourbopoulos A, Grigoriadis N, Higazi AA, et al. The plasminogen activator system: involvement in central nervous system inflammation and a potential site for therapeutic intervention. J Neuroinflammation. 2013;10(1):124.

5. Nizri E, Irony-Tur-Sinai M, Lory O, Orr-Urtreger A, Lavi E, Brenner T. Activation of the cholinergic anti-inflammatory system by nicotine attenuates neuroinflammation via suppression of Th1 and Th17 responses. J Immunol. 2009;183(10):6681-8. https://doi.org/10.4049/jimmunol.0902212.

6. Nizri E, Hamra-Amitay Y, Sicsic C, Lavon I, Brenner T. Anti-inflammatory properties of cholinergic up-regulation: a new role for acetylcholinesterase inhibitors. Neuropharmacology. 2006;50(5):540-7. https://doi.org/10.1016/j. neuropharm.2005.10.013.

7. Nizri E, Irony-Tur-Sinai M, Faranesh N, Lavon I, Lavi E, Weinstock M, et al. Suppression of neuroinflammation and immunomodulation by the acetylcholinesterase inhibitor rivastigmine. J Neuroimmunol. 2008;203(1):1222. https://doi.org/10.1016/j.jneuroim.2008.06.018.

8. Wang H, Yu M, Ochani M, Amella CA, Tanovic M, Susarla S, et al. Nicotinic acetylcholine receptor alpha7 subunit is an essential regulator of inflammation. Nature. 2003:421(6921):384-8. https:/doi.org/10.1038/nature01339.

9. Treinin M, Papke RL, Nizri E, Ben-David Y, Mizrachi T, Brenner T. Role of the alpha7 nicotinic acetylcholine receptor and RIC-3 in the cholinergic antiinflammatory pathway. Cent Nerv Syst Agents Med Chem. 2017;17(2):90-9. https://doi.org/10.2174/1871524916666160829114533.

10. Piao WH, Campagnolo D, Dayao C, Lukas RJ, Wu J, Shi FD. Nicotine and inflammatory neurological disorders. Acta Pharmacol Sin. 2009;30(6):715-22. https://doi.org/10.1038/aps.2009.67.

11. Reale M, Di Bari M, Di Nicola M, D'Angelo C, De Angelis F, Velluto L, et al. Nicotinic receptor activation negatively modulates pro-inflammatory cytokine production in multiple sclerosis patients. Int Immunopharmacol. 2015;29(1):152-7. https://doi.org/10.1016/j.intimp.2015.06.034.

12. Godin JR, Roy P, Quadri M, Bagdas D, Toma W, Narendrula-Kotha R, et al. A silent agonist of alpha7 nicotinic acetylcholine receptors modulates inflammation ex vivo and attenuates EAE. Brain Behav Immun. 2020;87:286300. https://doi.org/10.1016/j.bbi.2019.12.014.

13. Seguela P, Wadiche J, Dineley-Miller K, Dani JA, Patrick JW. Molecular cloning, functional properties, and distribution of rat brain alpha 7: a nicotinic cation channel highly permeable to calcium. J Neurosci. 1993;13(2): 596-604. https://doi.org/10.1523/JNEUROSCI.13-02-00596.1993.

14. Williams DK, Wang J, Papke RL. Positive allosteric modulators as an approach to nicotinic acetylcholine receptor-targeted therapeutics: advantages and limitations. Biochem Pharmacol. 2011;82(8):915-30. https:// doi.org/10.1016/j.bcp.2011.05.001

15. Thakur GA, Kulkarni AR, Deschamps JR, Papke RL. Expeditious synthesis, enantiomeric resolution, and enantiomer functional characterization of (4-4bromophenyl)-3a,4,5,9b-tetrahydro-3H-cyclopenta[c]quinoline-8-sulfonamide (4BP-TQS): an allosteric agonist-positive allosteric modulator of alpha7 nicotinic acetylcholine receptors. J Med Chem. 2013;56(21):8943-7. https:// doi.org/10.1021/jm401267t.

16. Bagdas D, Wilkerson IL, Kulkarni A, Toma W, AlSharari S, Gul Z, et al. The alpha7 nicotinic receptor dual allosteric agonist and positive allosteric modulator GAT107 reverses nociception in mouse models of inflammatory and neuropathic pain. $\mathrm{Br} J$ Pharmacol. 2016;173(16):2506-20. https:/doi.org/10.1111/bph.13528.

17. Quadri M, Garai S, Thakur GA, Stokes C, Gulsevin A, Horenstein NA, et al. Macroscopic and microscopic activation of alpha7 nicotinic acetylcholine receptors by the structurally unrelated allosteric agonist-positive allosteric modulators (ago-PAMs) B-973B and GAT107. Mol Pharmacol. 2018;95(1):4361. https://doi.org/10.1124/mol.118.113340.
18. Nizri E, Irony-Tur-Sinai M, Lavon I, Meshulam H, Amitai G, Brenner T. IBU-octylcytisine, a novel bifunctional compound eliciting anti-inflammatory and cholinergic activity, ameliorates CNS inflammation by inhibition of T-cell activity. Int Immunopharmacol. 2007;7(9):1129-39. https:/doi.org/10.1016/.jintimp.2007.03.009.

19. Nizri E, Brenner T. Modulation of inflammatory pathways by the immune cholinergic system. Amino Acids. 2013;45(1):73-85. https://doi.org/10.1007/ s00726-011-1192-8.

20. Van Kaer L, Postoak JL, Wang C, Yang G, Wu L. Innate, innate-like and adaptive lymphocytes in the pathogenesis of MS and EAE. Cell Mol Immunol. 2019;16(6):531-9. https://doi.org/10.1038/s41423-019-0221-5.

21. Krumbholz M, Derfuss T, Hohlfeld R, Meinl E. B cells and antibodies in multiple sclerosis pathogenesis and therapy. Nat Rev Neurol. 2012;8(11): 613-23. https://doi.org/10.1038/nrneurol.2012.203.

22. Claes N, Fraussen J, Stinissen P, Hupperts R, Somers V. B cells are multifunctional players in multiple sclerosis pathogenesis: insights from therapeutic interventions. Front Immunol. 2015;6:642.

23. Kurosaki T. Paradox of B cell-targeted therapies. J Clin Invest. 2008;118(10): 3260-3. https://doi.org/10.1172/JCl37099.

24. Wolf SD, Dittel BN, Hardardottir F, Janeway CA Jr. Experimental autoimmune encephalomyelitis induction in genetically B cell-deficient mice. J Exp Med. 1996;184(6):2271-8. https://doi.org/10.1084/jem.184.6.2271.

25. Fillatreau S, Sweenie CH, McGeachy MJ, Gray D, Anderton SM. B cells regulate autoimmunity by provision of IL-10. Nat Immunol. 2002;3(10):94450. https://doi.org/10.1038/ni833.

26. Matsushita T, Yanaba K, Bouaziz JD, Fujimoto M, Tedder TF. Regulatory B cells inhibit EAE initiation in mice while other B cells promote disease progression. J Clin Invest. 2008;118(10):3420-30. https://doi.org/10.1172/JCI3 6030.

27. Pierson ER, Stromnes IM, Goverman JM. B cells promote induction of experimental autoimmune encephalomyelitis by facilitating reactivation of $\mathrm{T}$ cells in the central nervous system. J Immunol. 2014;192(3):929-39. https:// doi.org/10.4049/jimmunol.1302171.

28. Molnarfi N, Schulze-Topphoff U, Weber MS, Patarroyo JC, Prod'homme T, Varrin-Doyer M, et al. MHC class II-dependent B cell APC function is required for induction of CNS autoimmunity independent of myelin-specific antibodies. J Exp Med. 2013;210(13):2921-37. https://doi.org/10.1084/jem.2 0130699.

29. Barr TA, Shen P, Brown S, Lampropoulou V, Roch T, Lawrie S, et al. B cell depletion therapy ameliorates autoimmune disease through ablation of IL6-producing B cells. J Exp Med. 2012;209(5):1001-10. https://doi.org/10.1 084/jem.20111675.

30. Prinz-Hadad H, Mizrachi T, Irony-Tur-Sinai M, Prigozhina TB, Aronin A, Brenner $T$, et al. Amelioration of autoimmune neuroinflammation by the fusion molecule Fn14.TRAIL. J Neuroinflammation. 2013;10:36.

31. Mizrachi T, Gur-Wahnon D, Al-Roof Higazi A, Brenner T. Role of tissue plasminogen activator in clinical aggravation of experimental autoimmune encephalomyelitis and its therapeutic potential. Cell Immunol. 2020;348: 104040. https://doi.org/10.1016/j.cellimm.2020.104040.

32. Ben-David Y, Kagan S, Cohen Ben-Ami H, Rostami J, Mizrahi T, Kulkarni AR, et al. RIC3, the cholinergic anti-inflammatory pathway, and neuroinflammation. Int Immunopharmacol. 2020;83:106381. https://doi.org/1 0.1016/j.intimp.2020.106381.

33. Clemente N, Raineri D, Cappellano G, et al. Osteopontin bridging innate and adaptive immunity in autoimmune diseases. J Immunol Res. 2016;2016:7675437.

34. Martiney JA, Rajan AJ, Charles PC, Cerami A, Ulrich PC, Macphail S, et al. Prevention and treatment of experimental autoimmune encephalomyelitis by CNI-1493, a macrophage-deactivating agent. J Immunol. 1998;160(11):5588-95.

35. Borovikova LV, Ivanova S, Zhang M, Yang H, Botchkina Gl, Watkins LR, et al. Vagus nerve stimulation attenuates the systemic inflammatory response to endotoxin. Nature. 2000;405(6785):458-62. https://doi.org/10.1038/35013070.

36. Gu SM, Park MH, Yun HM, Han SB, Oh KW, Son DJ, et al. CCR5 knockout suppresses experimental autoimmune encephalomyelitis in C57BL/6 mice. Oncotarget. 2016;7(13):15382-93. https://doi.org/10.18632/oncotarget.8097.

37. Gauthier AG, Wu J, Lin M, et al. The Positive Allosteric Modulation of alpha7Nicotinic Cholinergic Receptors by GAT107 Increases Bacterial Lung Clearance in Hyperoxic Mice by Decreasing Oxidative Stress in Macrophages. Antioxidants (Basel). 2021;10(1):135-53. https://doi.org/10.33 90/antiox10010135.

38. Lyons JA, Ramsbottom MJ, Cross AH. Critical role of antigen-specific antibody in experimental autoimmune encephalomyelitis induced by recombinant myelin oligodendrocyte glycoprotein. Eur J Immunol. 2002; 
32(7):1905-13. https://doi.org/10.1002/1521-4141(200207)32:7<1905::AIDIMMU1905>3.0.CO;2-L.

39. Svensson L, Abdul-Majid KB, Bauer J, Lassmann H, Harris RA, Holmdahl R. A comparative analysis of B cell-mediated myelin oligodendrocyte glycoprotein-experimental autoimmune encephalomyelitis pathogenesis in B cell-deficient mice reveals an effect on demyelination. Eur J Immunol. 2002;32(7):1939-46. https://doi.org/10.1002/1521-4141(200207)32:7<1939:A ID-IMMU1939>3.0.CO;2-S.

40. Genain CP, Cannella B, Hauser SL, Raine CS. Identification of autoantibodies associated with myelin damage in multiple sclerosis. Nat Med. 1999;5(2): 170-5. https://doi.org/10.1038/5532.

41. Mackay F, Silveira PA, Brink R. B cells and the BAFF/APRIL axis: fast-forward on autoimmunity and signaling. Curr Opin Immunol. 2007;19(3):327-36. https://doi.org/10.1016/j.coi.2007.04.008.

42. MacLennan I, Vinuesa C. Dendritic cells, BAFF, and APRIL: innate players in adaptive antibody responses. Immunity. 2002;17(3):235-8. https://doi.org/1 0.1016/S1074-7613(02)00398-9.

43. Thangarajh M, Masterman T, Hillert J, Moerk S, Jonsson R. A proliferationinducing ligand (APRIL) is expressed by astrocytes and is increased in multiple sclerosis. Scand J Immunol. 2007;65(1):92-8. https://doi.org/1 0.1111/j.1365-3083.2006.01867.x.

44. Agah E, Zardoui A, Saghazadeh A, Ahmadi M, Tafakhori A, Rezaei N. Osteopontin (OPN) as a CSF and blood biomarker for multiple sclerosis: a systematic review and meta-analysis. PLoS One. 2018;13(1):e0190252. https://doi.org/10.1371/journal.pone.0190252.

45. Reale M, de Angelis F, di Nicola M, Capello E, di loia M, Luca G, et al. Relation between pro-inflammatory cytokines and acetylcholine levels in relapsing-remitting multiple sclerosis patients. Int J Mol Sci. 2012;13(10): 12656-64. https://doi.org/10.3390/ijms131012656.

46. Gatta V, Mengod G, Reale M, Tata AM. Possible correlation between cholinergic system alterations and neuro/inflammation in multiple sclerosis. Biomedicines. 2020;8(6):153-68. https://doi.org/10.3390/biomedicines80601 53.

\section{Publisher's Note}

Springer Nature remains neutral with regard to jurisdictional claims in published maps and institutional affiliations.

Ready to submit your research? Choose BMC and benefit from:

- fast, convenient online submission

- thorough peer review by experienced researchers in your field

- rapid publication on acceptance

- support for research data, including large and complex data types

- gold Open Access which fosters wider collaboration and increased citations

- maximum visibility for your research: over $100 \mathrm{M}$ website views per year

At $\mathrm{BMC}$, research is always in progress.

Learn more biomedcentral.com/submissions 